\title{
Apontamentos dos registros cinematográficos referentes ao \\ Contestado
}

Ana Crhistina Vanali ${ }^{1}$

\section{RESUMO:}

O cinema reflete a mentalidade de seu tempo e acaba tornando-se fonte de pesquisa com possibilidades bastante amplas. Nesse artigo resgata-se os filmes documentários referentes à Guerra do Contestado que foram realizados no "calor dos acontecimentos" com o objetivo de analisar sua utilização política.

Palavras-chave: Cinema paranaense. Guerra do Contestado. Limites PR x SC.

\section{Notes of the cinematographic records relating to the Contestado}

\begin{abstract}
:
Cinema reflects the mentality of its time and ends up becoming a source of research with quite broad possibilities. In this article the documentary films related to the War of the Contestado are rescued that were realized in the "heat of the events" with the objective to analyze its political use.
\end{abstract}

Keywords: Paranaense cine. Contestant War. PR x SC limits

- Enviado em 13/05/2017

- Aprovado em 28/06/2017

${ }^{1}$ Doutora em Sociologia pela UFPR. E-mail: anacvanali@yahoo.com.br 
Em 6 de junho de 1908 era inaugurado o primeiro cinema de Curitiba ${ }^{2}$, o Smart Cinema, localizado na Rua XV de Novembro, 67. Era de propriedade de Anníbal Rocha Requião ${ }^{3}$. Em suas sessões diárias eram exibidos os próprios filmes de Requião e outros nacionais e estrangeiros. Em 1911 as instalações do Smart são ampliadas e detalhadamente descritas pelos jornais da época (A República, 28/09/1911). Curitiba crescia e se transformava através de sua rede de transportes, com a chegada dos bondes elétricos e da fundação da Universidade do Paraná, em 1912. A capital ganhava um ar de centro cultural e intelectual, no qual a ampliação e sofisticação das salas de cinema tinha um papel importante, pois esses espaços eram frequentados pelas personalidades da sociedade.

O Cine Smart sofria concorrência do Eden Paranaense e do Coliseu Curitibano que teve o nome alterado para Theatro Polytheama (Figura 1). Mas, de acordo com a imprensa da época, o Smart era o de maior frequência e suntuosidade e para manter esse prestígio da sala, Requião sempre trazia novidades como sessões diárias, filme de arte e matinadas infantis (Figura 2).

\footnotetext{
${ }^{2}$ No final da primeira década do século XX Curitiba já contava com sete locais de exibição cinematográfica entre teatros, parques e um cinema - o Smart (Diário da Tarde, 30/06/1908).

${ }^{3}$ Anníbal Rocha Requião (1875-1929) foi fotógrafo, dono de livraria e dono do primeiro cinema de Curitiba. Seu primeiro filme "Desfile militar de 15 de novembro" marcou o nascimento do cinema paranaense em 1907 (Diário da Tarde, 19/11/1907). Ainda nesse ano registra a chegada do primeiro automóvel na cidade pertencente à família Fontana. Sua produção cinematográfica passa de dois filmes em 1907 para 18 em 1909. As filmagens de Requião não ficam restritas à capital paranaense. Ele viaja pelo interior do estado para registrar aspectos da vida interiorana e da natureza. Seus filmes tiveram como tema os acontecimentos oficiais e paisagens do Estado. A produção de Requião começa a diminuir em 1912, ano em que registra apenas 3 filmes. Pouco se sabe de sua vida após 1914. Em 1913 o Cine Smart foi reformado e ampliado, tornando-se o mais elegante e espaçoso cinema da cidade. A partir de 1917 os anúncios do Cine Smart somem dos jornais, nãos sendo possível saber se foi vendido ou se encerrou suas atividades. Em 1918 Requião sofre um infarto, ficando com sérios problemas de saúde, vindo a falecer em 1929 (STECZ \& KARAM, 1980).
} 
Ao terminarmos estas linhas enviamos á empreza do Eden os nossos parabens pela posição que hoje occupa o correcto parque como centro necessario de diversão.

COLISEO - O sympathico logradouro teve as costumeiras visitas do nosso publico, regorgitando nas noites de funcção.

No cynematographo foram exhibidas novas vistas que bastante agradaram.

SmaRT CINEMA-Inaugurou-se sabbado passado - Smart Cinema, á rua 15 n. 67. Este novo ponto de diversð̃es attrahio a nossa elite, sendo pequeno para conter o grande numero de espectadores que afluiram.

O salăo está elegantemente arranjado, ou por outra está up to deit.

As vistas exhibidas agradaram bastante.

O Cinemu Smart funcciona diariamente apresentando sempre programmas variados.

Figura 1- Inauguração do Cinema Smart

Fonte: O Olho da Rua, 13/06/1908

\section{SmarT. - Sempre na ponta ! Vis- tas noras todos os dias! \\ A Empreza do Annibal e do Getu- lio-que sempre se prenccupa em contentar os seus innumeros habi- tués, de tanta fila nova que tem apresentado. recebeu honlem o te. legramma seguinte do l'alhé e do Gaumout: Basla de filas novas. Stock acabou-se. Assion não ha... costas que aguentern.}

Figura 2- Novidades do Cinema Smart

Fonte: O Olho da Rua, 01/01/1909 
A frequência aos cinemas era grande no início do século XX. As salas intercalavam em sua programação filmes nacionais e estrangeiros e procuravam atrair o público com promoções, brindes e atrações. Mas não eram só as promoções festivas que movimentavam os cinemas de Curitiba. Embora voltados à diversão, eles não poderiam ignorar um importante acontecimento que estava ocorrendo: a disputa de limites entre os estados do Paraná e de Santa Catarina e nem a Guerra do Contestado que se estendeu de 1912 a 1916.

No dia 22 de outubro de 1912 ocorreu o Combate do Irani onde o coronel João Gualberto (comandante das forças policiais paranaenses - Figura 3) e o monge João Maria (Figura 4) foram mortos. A morte do coronel João Gualberto e de mais 21 soldados paranaenses em Irani sensibilizou a população e atingiu os cinemas que, em sinal de luto, mantiveram as portas fechadas. O Smart reabriu com dois filmes de Anníbal Requião: um que mostrava a partida do Regimento de Segurança para Palmas e o outro sobre os funerais do coronel das forças policiais paranaenses (Anexo A):

Theatros, cinemas e salões: reabrem-se hoje todas as casas de diversões que haviam suspendido seus atractivos em sinal de lucto. 0 Smart Cinema funcionará em seção permanente até as 8 horas sendo o produto das entradas em benefício das famílias que morreram no combate nos campos de Irani. No programa figurará a fita representando a partida do Regimento de Segurança para Palmas (Commercio do Paraná, 26/10/1912).

Durante o mês de outubro de 1912 o Cine Smart realizou sessões permanentes destinando a renda às famílias dos soldados mortos em combate no Campos de Irani. No dia 26 de novembro foi exibido o filme "Partida do Regimento de Segurança para Palmas"4 realizado por Requião.

\footnotetext{
4 O filme "Partida do Regimento de Segurança para Palmas" está desaparecido. Sua ficha técnica por ser consultada no sítio da Cinemateca Brasileira http://bases.cinemateca.gov.br/cgibin/wxis.exe/iah/?IsisScript=iah/iah.xis\&base=FILMOGRAFIA\&lang=P\&nextAction=search\&exprSearch=ID=001283 \&format=detailed.pft. Acesso 28.maio.2017.
} 


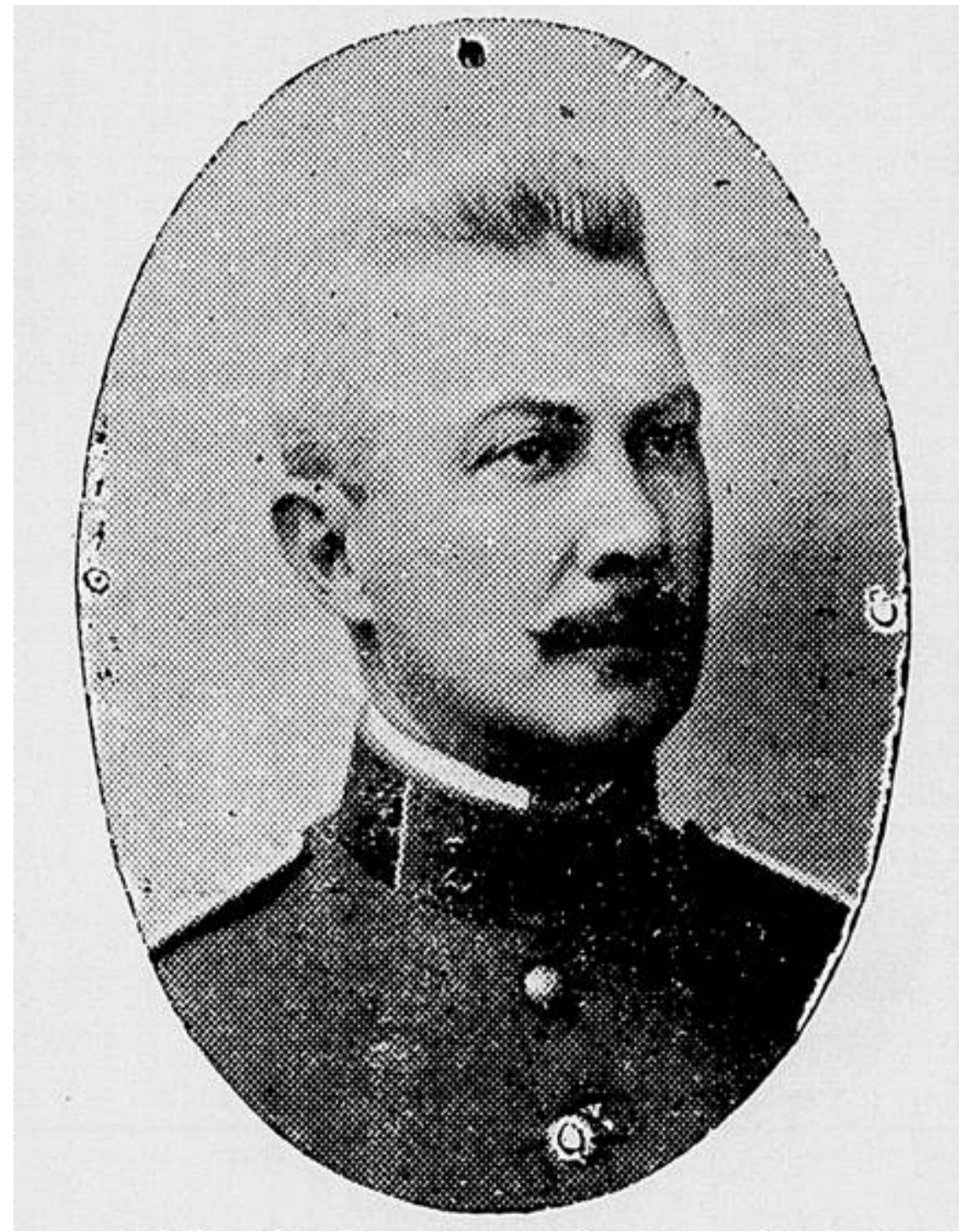

Figura 3 - João Gualberto Gomes de Sá5

Fonte: O Olho da Rua, 10/06/1911

${ }^{5}$ Ainda está para ser feito um estudo biográfico de referência sobre João Gualberto. 


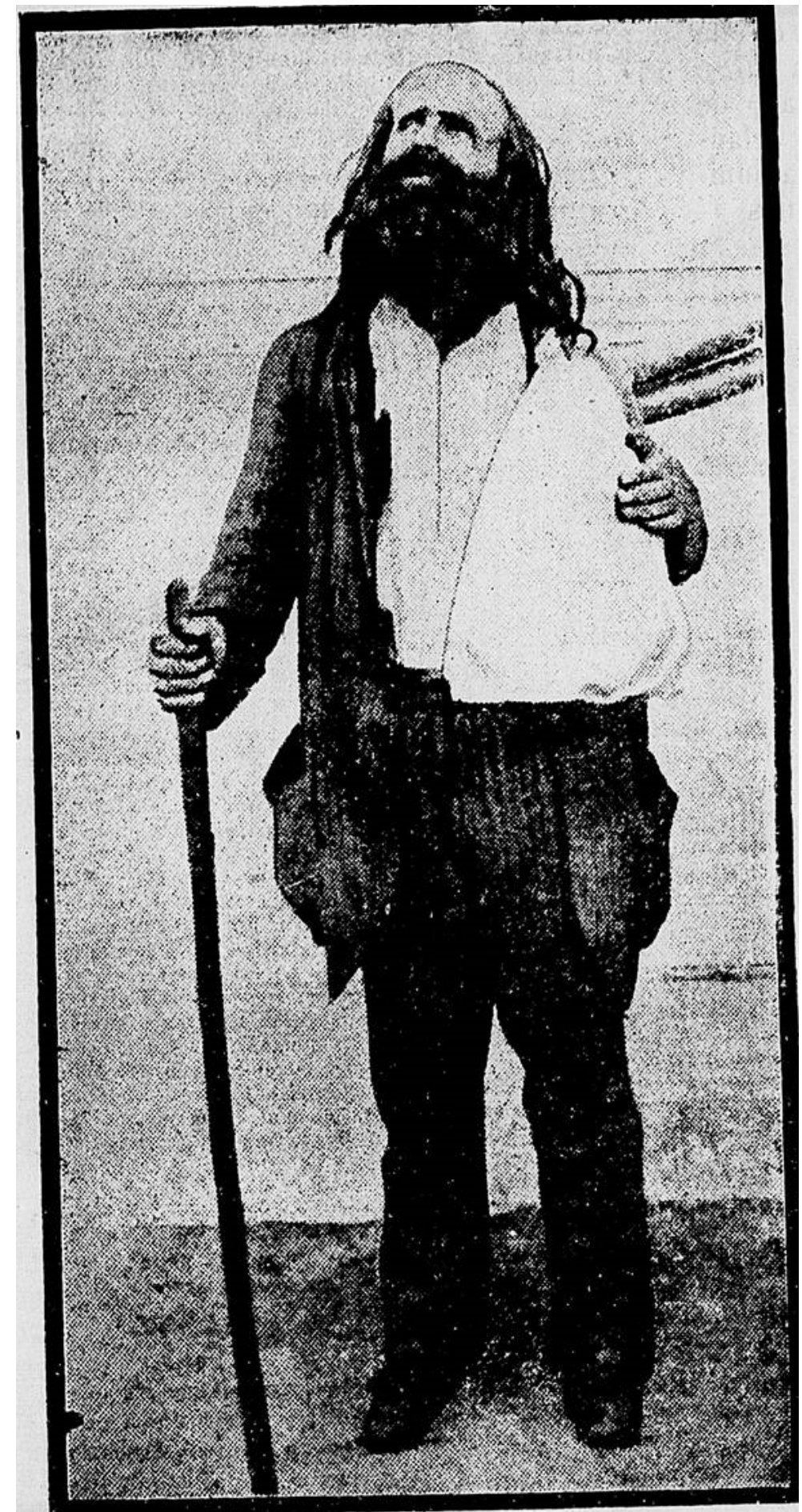

Figura 4 - Monge João Maria 6

Fonte: O Olho da Rua, 14/10/1911

${ }^{6}$ Para saber mais sobre a figuras dos monges no Contestado consultar: KARSBURG, Alexandre (2014). 0 eremita das Américas: a odisseia de um peregrino italiano no século XIX. Santa Maria/RS: Editora UFSM. 
Nos dias 8 e 9 de novembro de 1912 foi exibido no Cine Smart o outro filme de Anníbal Requião, "A chegada e funeraes do Coronel João Gualberto"7 mostrando o cortejo saindo da Sociedade Tiro Rio Branco, ladeado por multidão, e a salva de tiros na Praça Tiradentes.

Witoslawski indica que o prestígio conquistado por João Gualberto, junto à sociedade curitibana, muito se deveu a sua inserção na Sociedade de Tiro fundada em 1o de junho de 1909. O militar soube, como poucos, articular as esferas civil e militar, concepção de trabalho que levou seu nome a ser cogitado para prefeito de Curitiba. A disputa pela indicação do cargo estava entre João Gualberto e o engenheiro Cândido de Abreu. Com a morte prematura do militar em 1912, por ocasião da Guerra do Contestado, o cargo acabou com Cândido de Abreu. João Gualberto representava o ideal da nova república e a instituição fundada por ele seria primordial para ajudar na criação de um sentimento de nação, conformando nos corpos dos jovens curitibanos valores cívicos que um "pequeno soldado" necessita: "(...) o batalhão de caçadores de Coritiba foi inteiramente organizado com elementos civis, (excepção dos instructores) e tudo que elle possue, de tambores a officiaes, representa a somma de muita dedicação, boa vontade e civismo da mocidade paranaense (...)"(Diário da Tarde, 01/11/1909). O Diário da Tarde afirmava a ideia que o Tiro Rio Branco estava cumprindo o seu papel na nacionalização da mocidade curitibana. A criação da instituição teve o intuito de quebrar a hegemonia dos imigrantes, principalmente alemães, que dominavam em suas associações a prática do Tiro. Mas ela visava, sobretudo, transformar toda a multiplicidade étnica existente no Paraná em curitibanos - paranaenses - brasileiros.

Stecz (1988) aponta que apesar da preferência de Anníbal Requião ser por filmagens de assuntos cívicos e militares, não são conhecidas referências sobre filmagens da Guerra do Contestato feitas por ele. Requião já havia filmado em Porto União, um ano antes do início da Guerra do Contestado, a ponte metálica sobre o Rio Iguaçu que foi exibido em 12 de outubro

\footnotetext{
7 Disponível em https://filmow.com/fatos-historicos-do-tiro-de-guerra-19-rio-brancot224244/trailers/172528/. Acesso 28.maio.2017. Este filme foi incluído como trecho no filme "Fatos Históricos do Tiro de Guerra 19 Rio Branco" que tem duração total de 6 minutos e 58 segundos. A partir dos 6 minutos e 11 segundos inicia a parte "Funeraes do Cel. João Gualberto, comandante do Tiro 19 em 1912". Ver Anexo B.

O filme "Fatos Históricos do Tiro de Guerra 19 Rio Branco" mostra: a chegada à Curitiba do Tiro de Guerra 19 Rio Branco, após ter conquistado no Rio de Janeiro a 7 de setembro de 1910, o primeiro lugar entre todos os Tiros do Brasil. 0 desfile de soldados, a revista da tropa e a apresentação das armas. 0 coronel João Gualberto Gomes de Sá Filho fazendo a entrega da Bandeira Nacional ao comandante do Destroier Paraná, em solenidade na qual discursa. 0 Destroier no cais de Paranaguá, detalhes do convés da embarcação. E por último o funeral do coronel João Gualberto em 1912, com cortejo saindo do Tiro de Guerra, ladeado por multidão, e a salva de tiros na Praça Tiradentes.
} 
de 1911 no Cine Smart ${ }^{8}$. Ele não voltou à região durante o conflito para registrar passagens do combate, como faria anos mais tarde o paranaense João Batista Groff, que acompanhando as tropas durante a Revolução de 1930, realizou o filme "Pátria redimida".

Sobre o Contestado existe apenas a referência de um registro fílmico: "Na região dos fanáticos: os fanáticos de Taquarussu" ${ }^{\prime}$, que descrevia a região dos conflitos e o movimento das tropas do general Carlos Frederico de Mesquita. 0 filme foi feito pelo gaúcho Emilio Soares Guimarães que partiu em "excursão cinematográfica” para a localidade de Taquarussu, no município de Curitibanos/SC, no final de abril de 1914 e retornou a Porto Alegre para finalizar o filme no final de junho. A sua exibição ocorreu em Porto Alegre no cinema Apollo, em 15 e 16 de julho de 1914 (TRUSZ, 2011). Em Curitiba foi lançado no Mignon Theatre em 10 de agosto de 1914 e exibido em seguida no Cine Smart. Conforme o Commercio do Paraná de 21 de Agosto de 1914:

Parques e Cinemas - Mignon: aos habitués do Mignon foi apresentado hontem o bem elaborado filme: Na região dos fanáticos. Trabalho feito com verdadeiro esmero esse filme é o completo atestado do esforço despendido pelo arrojado photocinematograhista, Sr. Guimarães que com muita felicidade apanhou scenas principais do movimento dos fanáticos na região de Taquarussu. Foi enfim, um sucesso, tanto para o Mignon quanto para o Sr. Guimarães, a estrea desse esplendido filme.

Smart: secundando o triumpho alcançado pelo Mignon o Smart projetou em sua tela o film: Na região dos fanáticos, alcançando idêntico sucesso. A assistência numerosa e chic saiu satisfeita.

O filme foi também exibido com os títulos "Na região dos fanáticos" ou "As forças expedicionárias do Sul”. Conforme alguns jornais curitibanos da época:

"Os fanáticos de Taquarussu", grande fita descritiva da região assolada pelos fanáticos, movimento das forças comandadas pelo General Carlos Frederico Mesquita (Diário da Tarde, 19/08/1914).

\footnotetext{
${ }^{8} 0$ filme "Porto União: ponte metálica sobre o Rio Iguaçu" está desaparecido. Sua ficha técnica por ser consultada no sítio da Cinemateca Brasileira http://bases.cinemateca.gov.br/cgi$\underline{\text { bin/wxis.exe/iah/?IsisScript=iah/iah.xis\&base=FILMOGRAFIA\&lang=P\&nextAction=search\&exprSearch=ID=00 }}$ 1155\&format=detailed.pft. Acesso 28.maio.2017.
}

${ }^{9}$ A fita está desaparecida, porém há muitos registros sobre o filme no acervo da Cinemateca de São Paulo. Ela é também referida pelos seguintes títulos: "As forças expedicionárias do Sul" e "Na região dos fanáticos".

Foi Emílio Guimarães quem realizou o filme "Funerais do senador Pinheiro Machado no RS" (1915) exibido no Cine Smart em 12 de janeiro de 1916. 
Neste filme se aprecia toda a região que estava ocupada pelos jagunços e que as tropas federais e, estaduais desalojaram além de diversos quadros com os acampamentos das tropas, marcha de artilharia, cavalaria e infantaria. Se vêem fases do combate e em uma delas se vê a morte do sargento Ivo. Filme patriótico (Commercio do Paraná, 20/08/1914).

Exibido em São Paulo em 15 de dezembro de 1914, o filme não alcançou sucesso, tendo inclusive sido retirado de cartaz:

O Royal, mantendo sua tradição de honestidade declara ter retirado de sua tela om filme Na região dos fanáticos, por ter verificado não corresponder o mesmo ao reclame com que fora oferecido (BERNARDET, 1979, p. 35)

Em 12 de setembro de 1914, A Lanterna publicou uma crônica, intitulada "Fanáticos versus fanáticos: a proposta dum filme cinematográfico"10, que exibe uma crítica bastante interessante sobre o filme "Os fanáticos de Taquarussu". 0 massacre de Taquarussu foi apenas um episódio da Guerra do Contestado. Taquarussu era um dos redutos dos sertanejos e sofreu dois ataques. No primeiro, em dezembro de 1913 a vitória foi dos sertanejos. No segundo, ocorrido no dia 8 de fevereiro de 1914, foi destruído pelo exército. Em abril de 1914, o general Carlos Frederico Mesquita, veterano da Guerra de Canudos, assumiu o comando das tropas federais. Após várias batalhas contra os sertanejos, desincumbe-se da missão e redige a seguinte carta aos seus superiores:

Tendo cumprido a minha missão, solicitei o regresso das Forças aos quartéis por se acharem estas extenuadas e sem roupas, e grande parte atacada de reumatismo e bronquite, devido a passar mal com a estação. ... Aos governos do Paraná e Santa Catarina competem, agora, com suas forças policiais, exterminar os bandidos que aparecerem, limpando assim a zona de elementos perniciosos. Em parte, a culpa é dos referidos governos, que descuram da instrução, deixando a ignorância campear livremente, chegando o fanatismo a constituir o grupo, como o que acabo de aniquilar numa luta inglória. (Mesquita, apud Mocellin, 1989, p. 29).

10 Uma semana após a publicação da crônica, "Fanáticos versus Fanáticos: a proposta dum film cinematográfico", A Lanterna publicou um outro artigo sobre Taquarussu intitulado "Os fanáticos de Lages", de autoria de um cronista da região. 
A visão do general Mesquita sobre a necessidade de serem exterminados os bandidos da região do Contestado, somada às avaliações que apontavam a falta de instrução dos sertanejos como uma das causas da fatalidade da guerra, estavam presentes em boa parte das análises feitas pela grande imprensa do período sobre o episódio. As elites rurais e urbanas, mergulhadas na racionalidade radical daquele período, justificavam os genocídios ocorridos em Canudos e no Contestado como uma reação natural e necessária à manifestação de comportamentos por elas tidos como irracionais, como os de "fanatismo", por exemplo.

A narrativa dos episódios do filme mostra duas forças opositoras: os sertanejos religiosos e o exército que os combate. No filme, o desfecho da revolta é marcado pela vitória do exército. As cenas destacam o heroísmo do exército e o amor à pátria. 0 exército é 0 representante da bandeira, do Estado e da religião. Os soldados devem ser tratados como heróis, pois combatem os fanáticos que devem ser aniquilados para que a ordem, a disciplina e o progresso civilizador possam triunfar. Já para o cronista a religião e o dinheiro são as causas dos males existentes na sociedade moderna e devem ser combatidos. 0 patriotismo, a religião e a ganância pelo lucro eram alvos bastante frequentes dos artigos publicados pela $\mathrm{A}$ Lanterna. Em lugar desses valores, outros eram apresentados e encorajados: o livre pensamento, o anticlericalismo e o ideal de nova sociedade mais justa.

A falta de raciocínio e de educação é apontada como a principal responsável pelos "episódios de carnificina" representados no filme. Para o cronista, somente a educação, o livro, mais especificamente, proporcionaria ao letrado a possibilidade do cultivo de outros valores, que não os apregoados pelo filme.

Em nossa pesquisa, não tivemos oportunidade de analisar os filmes do período, pois, eles não existem mais. Porém, a investigação histórica ainda pode ser feita através dos diferentes periódicos que registravam a programação do cinema e a realização dos filmes nessa época e que contribuem, ainda que modesta, para a história do cinema além do registro dos movimentos sociais no Brasil, no início do século XX. Por meio desses periódicos é possível recuperar e registrar parte da história de uma experiência concreta: a resistência sertaneja à dominação ideológica que procurava a conformação do trabalhador segundo os interesses do capital. 


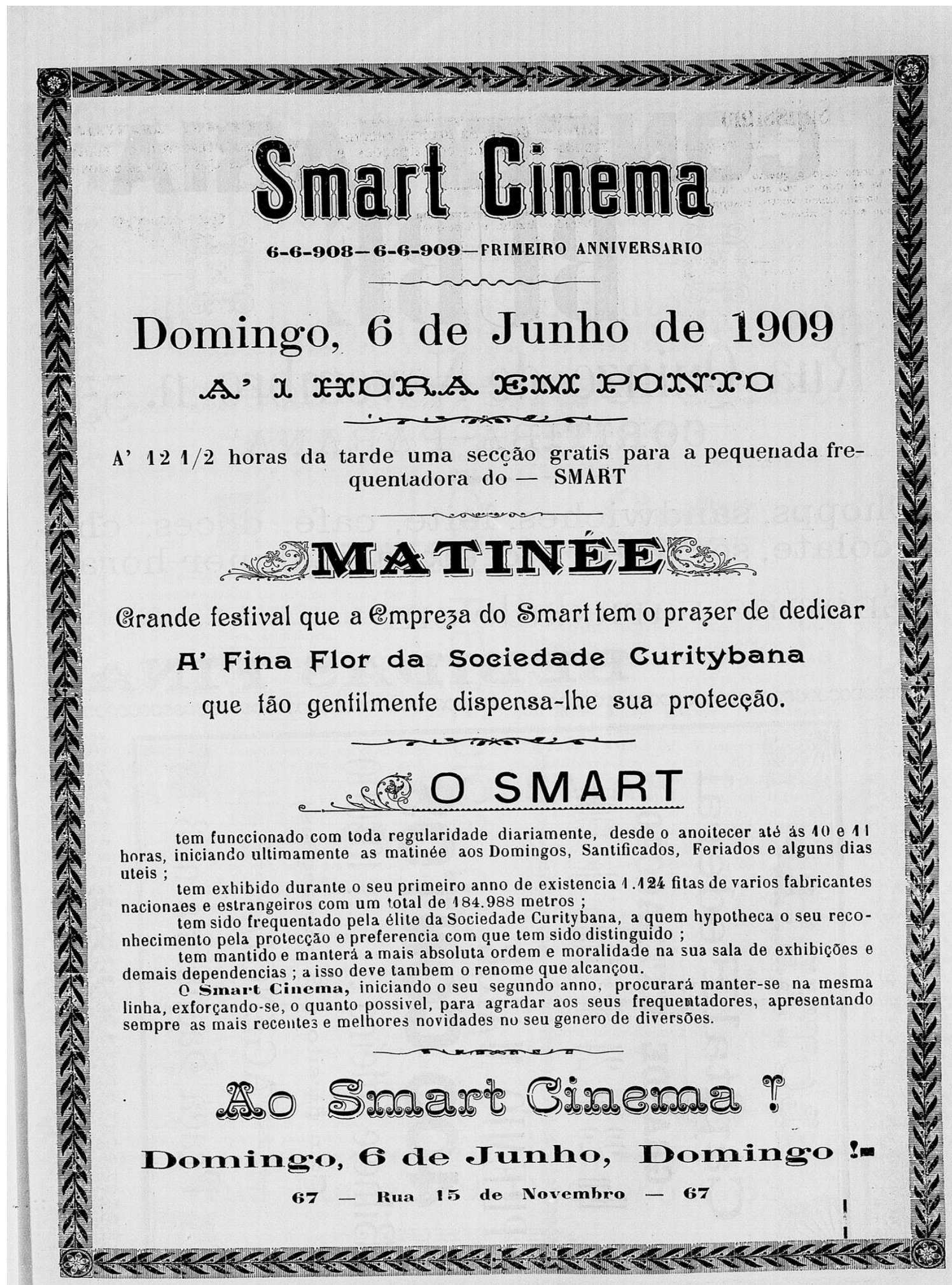

\section{Primeiro aniversário do Cine Smart}

Fonte: O Olho da Rua, 05/06/1909 


\section{REFERÊNCIAS}

BERNARDET, Jean-Claude (1979). Filmografia do cinema brasileiro (1900-1935). SP: Secretaria de Estado da Cultura.

MOCELLIN, Renato (1989). Os guerrilheiros do Contestado. São Paulo: Ed. do Brasil.

STECZ, Solange Straube (1988). Cinema paranaense (1900-1930). Curitiba: Dissertação História UFPR.

STECZ, Solange Straub e KARAM, Elizabeth (1980). Com Annibal Requião nasce o cinema no Paraná. IN: Cinema brasileiro, oito estudos. Rio de Janeiro, MEC/Embrafilme/Funarte, p. 89-107.

TRUSZ, Alice Dubina (2011). Emílio Guimarães: as múltiplas identidades de um produtor de imagens no Brasil dos anos de 1910. IN: Significação, № 36, p.55-85.

WITOSLAWSKI, Henrique (2009). Discursos sobre modernização e militarização juvenil em Curitiba (1919-1928). Curitiba (PR): Dissertação História UFPR.

\section{SITES}

Cinemateca Brasileira

Biblioteca Nacional 
ANEXO A

Fotos da partida do Regimento de Segurança para Palmas e os funerais do Coronel João Gualberto.

Fonte: Gazeta do Povo de 27/10/2010

Disponível em http://www.gazetadopovo.com.br/vida-e-cidadania/colunistas/nostalgia/imagens-de-umepisodio-civico-ah8qtjvt87a2zng2av4ixrmfi. Acesso 28.maio.2017.

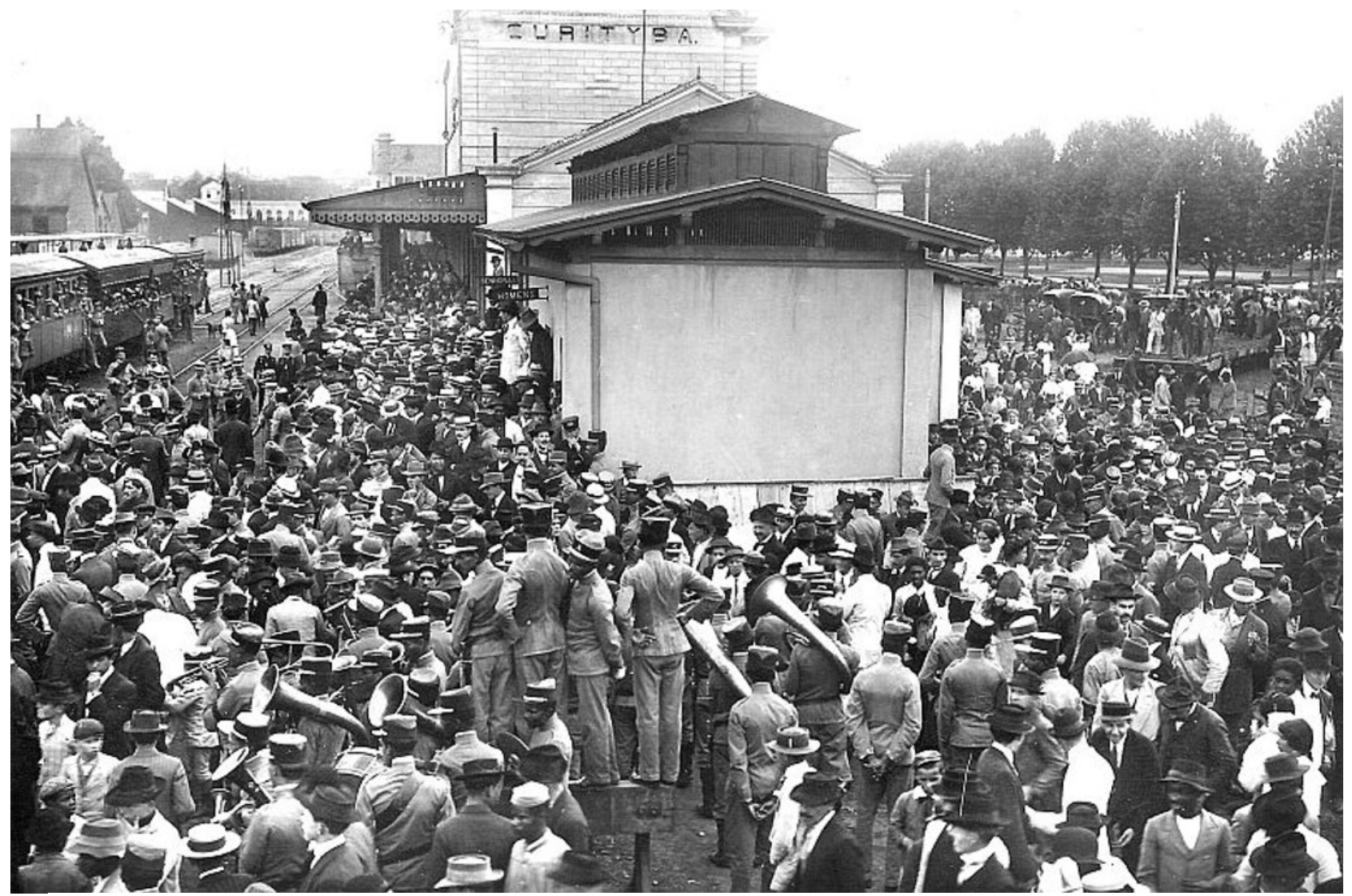

Na Estação da Estrada de Ferro, partida da tropa que participaria no que seria chamada de Campanha do Contestado. Foto de 1912 


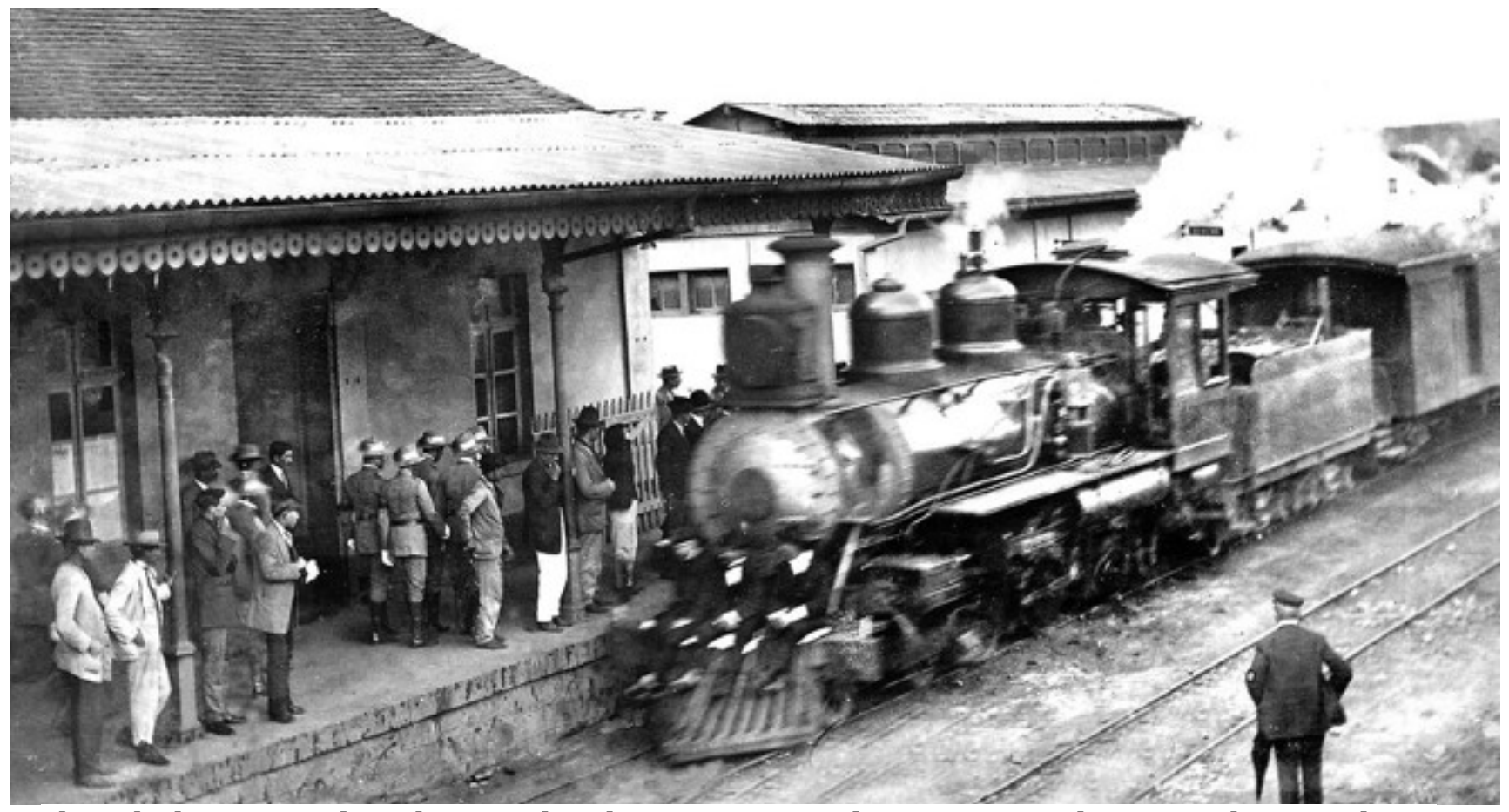

Chegada do trem, no dia 6 de novembro de 1912, em Curitiba, transportando o corpo do coronel João Gualberto, morto no Irani dia 20 de outubro.

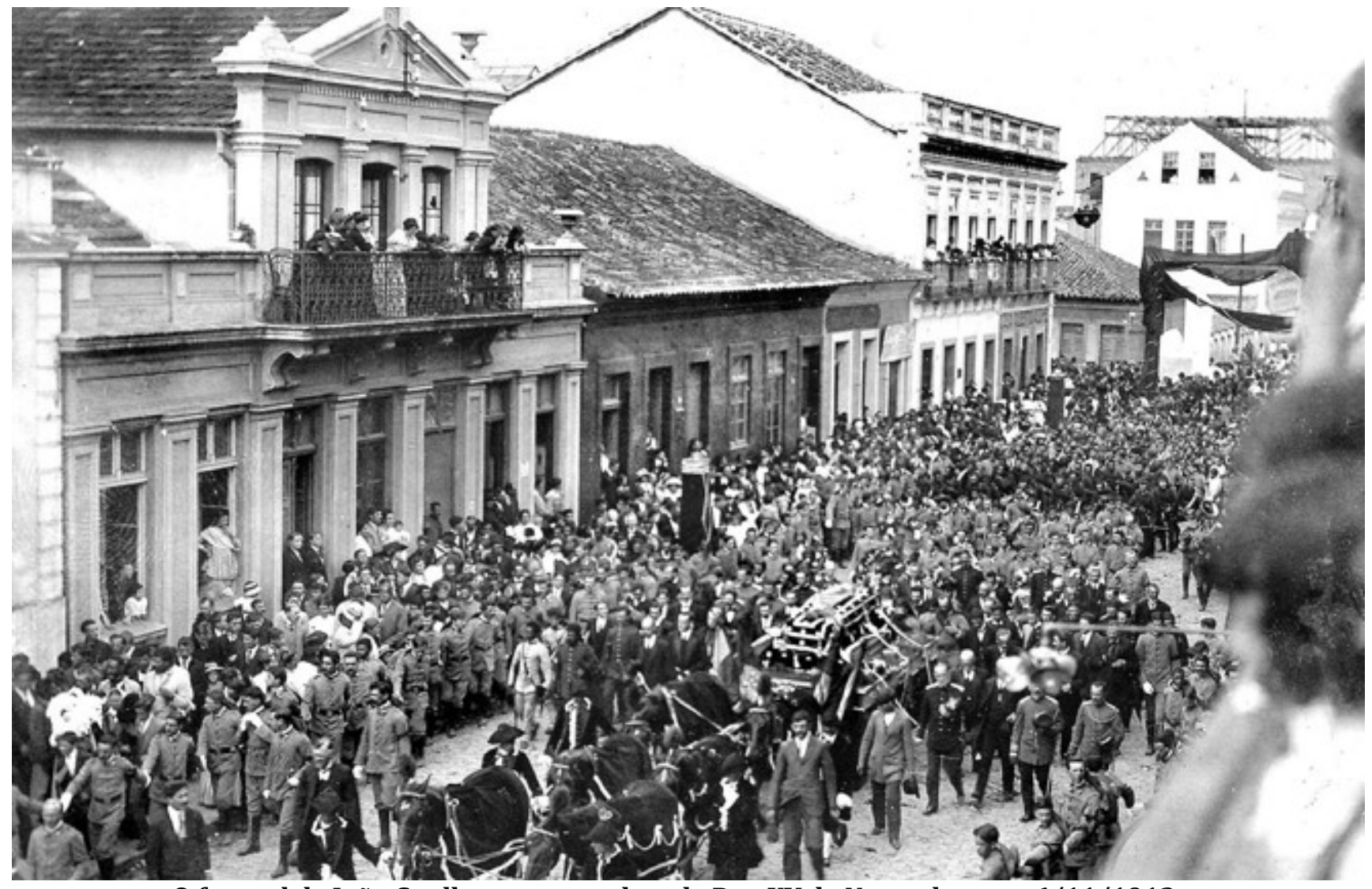

$O$ funeral de João Gualberto passando pela Rua XV de Novembro, em 6/11/1912 


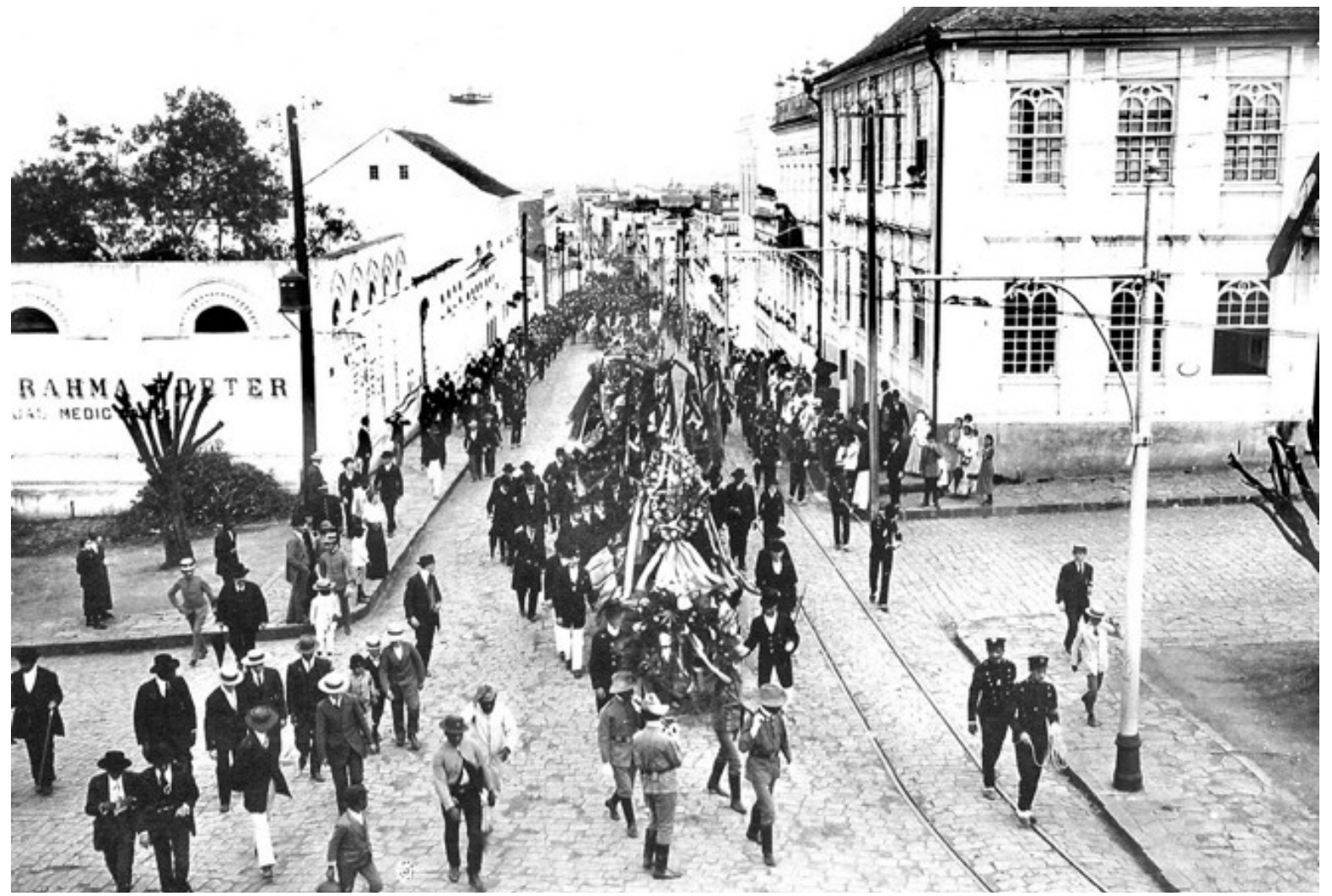

o enterro passando pela Rua do Rosário, em direção ao Cemitério Municipal. Foto do dia 7/11/1912

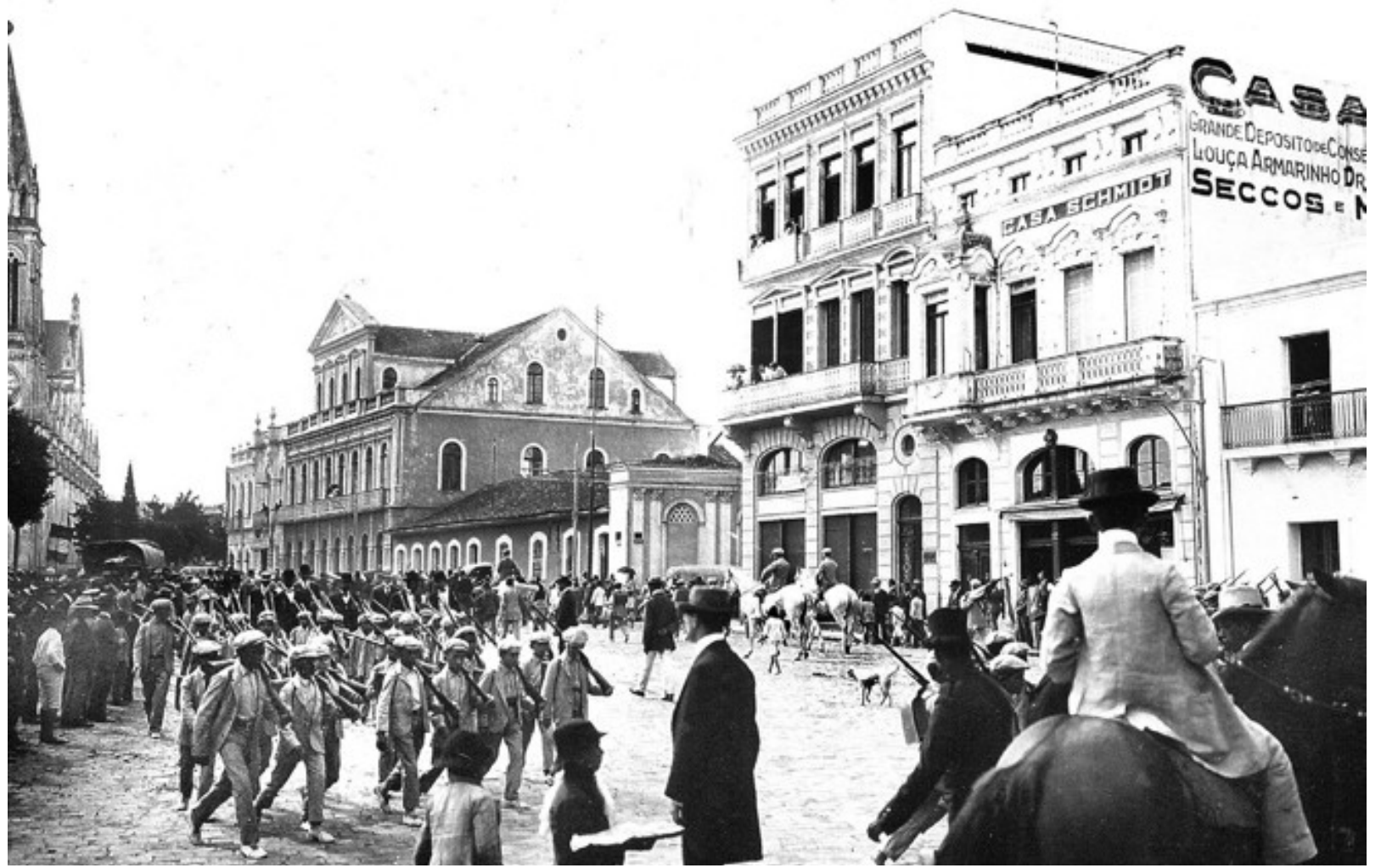

Alunos da Escola de Aprendizes Artífices desfilam pela Praça Tiradentes com destino à Rua da Graciosa, que passaria então para a denominação de Avenida João Gualberto, em 21 de abril de 1913 


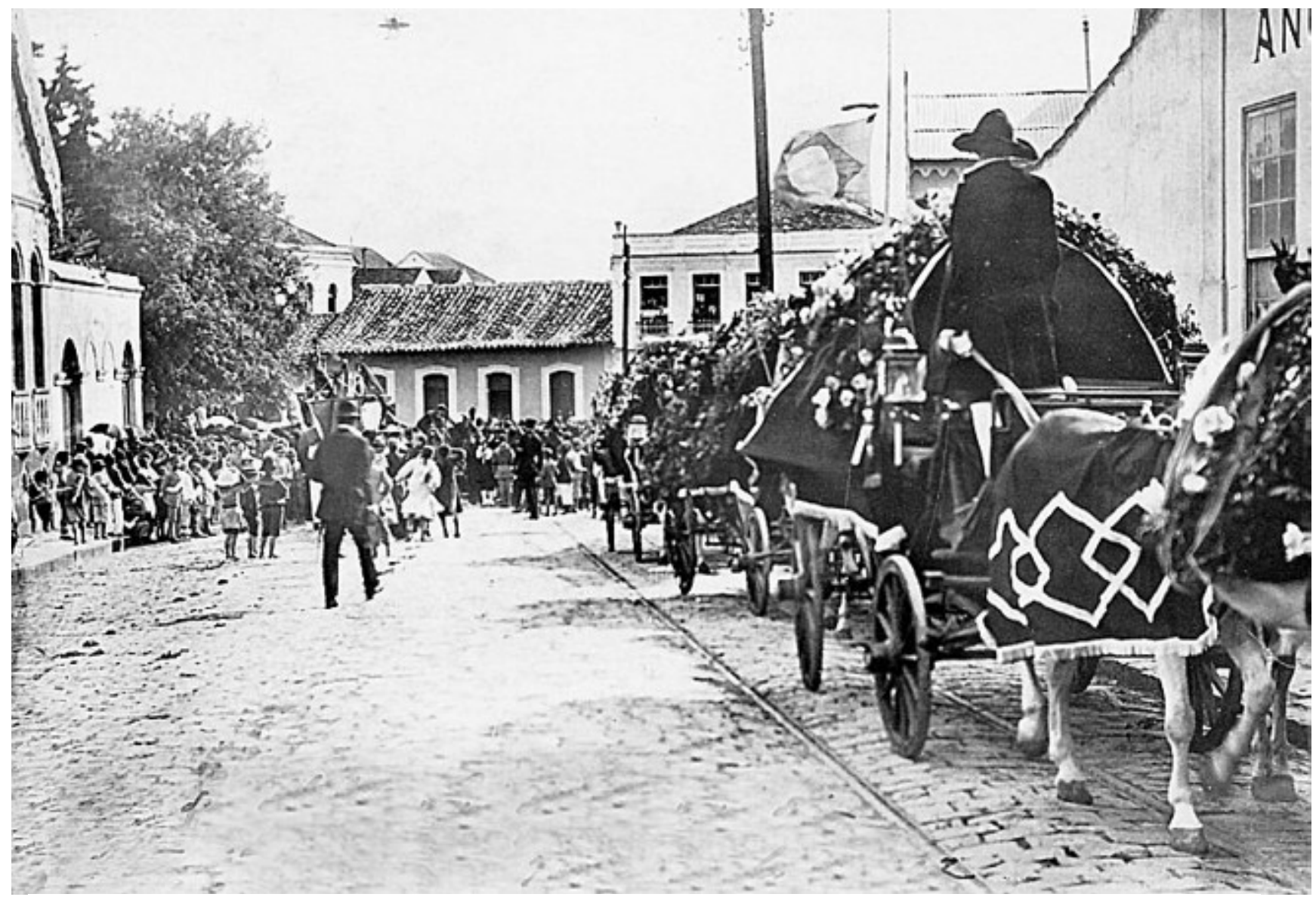

Vários coches fúnebres estacionados na Rua Alegre, atual Cândido de Leão, portando coroas de flores e esperando para acompanhar o enterro do corpo de João Gualberto, que estava sendo velado no Quartel do Tiro Rio Branco, fundado pelo infausto militar. Foto do dia 7 de novembro de 1912 


\section{ANEXO B \\ Ficha Cinemateca Brasileira \\ CHEGADA E FUNERAIS DO CORONEL JOÃO GUALBERTO}

Outras remetências de título:

CHEGADA DOS FUNERAIS DO CORONEL JOÃO GUALBERTO

Categorias: Curta-metragem / Silencioso / Não ficção

Material original: $35 \mathrm{~mm}, \mathrm{BP}, 16 \mathrm{q}$

Data e local de produção

Ano: 1912

País: BR

Cidade: Curitiba

Estado: PR

Data e local de lançamento

Data: 1912.11 .08

Local: Curitiba

Sala(s): Smart

\section{Sinopse}

Funerais do coronel João Gualberto Gomes de Sá Filho.

Gênero: Documentário

Termos descritores

Morte; Gualberto, João

\section{Descritores secundários}

Funeral; Guerra do Contestado

\section{Fotografia}

Operador: Requião, Annibal

Conteúdo examinado: $\mathrm{S}$

\section{Fontes utilizadas:}

MGV/P citando Comércio do Paraná, 08.11.1912

SSS-EK/AR

Observações: Este filme foi total ou parcialmente incluído em <FATOS HISTÓRICOS DO TIRO DE GUERRA 19 RIO BRANCO>, 1910-1912.

Fonte: 